\title{
A EXPANSÃO DA PECUÁRIA NA AMAZÔNIA
}

\author{
Leonela Guimarães da Silva ${ }^{1}$
}

RESUMO: Este trabalho tem por objetivo apresentar o contexto inicial da inserção econômica da pecuária da Amazônia. Atualmente observa-se a concentração da agroindústria de exportação nessa região e as mudanças que essa agroindústria tem promovido na pecuária regional, em termos de transformações técnicas para oferecer matéria-prima de qualidade e com preços competitivos. Mas Essa agroindústria de exportação tem submetido a produção de carne bovina da região às exigências do mercado internacional. Desta forma, tornou-se relevante uma análise que apresente como a pecuária, hoje, consolidada na região amazônica, tem seu processo inicial alicerçado em uma política governamental, a saber, do regime militar, que com o objetivo inicial de ocupação dessa região, encontra na atividade pecuária "a melhor forma" para ocupar a região.

PALAVRAS-CHAVE: Pecuária na Amazônia, Política de desenvolvimento regional, Regime Militar.

ABSTRACT: This work aims to present the initial context of economic integration of livestock Amazon. Currently there is a concentration of agribusiness exports in this region and the changes that agribusiness has promoted regional livestock in terms of technical changes to provide feedstock quality and competitively priced. But this agribusiness exports has undergone beef production in the region to meet international market requirements. Thus, it became important to present an analysis as livestock, today consolidated in the Amazon region, has its initial process rooted in government policy, namely, the military regime, which meets the initial goal of occupation of this region, livestock activity "the best way" to occupy the region.

KEYWORDS: Livestock in the Amazon, Regional development policy, Military Regime,

\section{INTRODUÇÃO}

Segundo Becker (2005) o povoamento e desenvolvimento da Amazônia foram fundados de acordo com o paradigma de relação sociedade-natureza que Kenneth Boulding denomina de "economia de fronteira". Isso significa que o crescimento econômico é visto como linear e infinito, e baseado na contínua incorporação de terra e de recursos naturais, que são também percebidos como infinitos. Para Autora esse paradigma caracteriza toda a formação latino-americana, e esse padrão de desenvolvimento alcançou o auge, na Amazônia, entre 1960 e 1980.

Fundado nesse paradigma o desenvolvimento da região, entre as décadas de $60 \mathrm{e}$ 80 , estava ligado a chegada do capital, a instalação de infraestrutura, ocupação humana e territorial. A derrubada da floresta era vista com um processo necessário. Neste sentido para Paula (2008) a Amazônia tem sido uma reserva estratégica de riquezas de que o capital,

1 Professora da Faculdade de Economia (FE-UFMT). Graduada em Ciências Econômicas (UFSM) e Mestre em Planejamento do Desenvolvimento (NAEA-UFPA) 
intermitentemente, lançou mão para a produção de superlucros com a exploração das drogas do sertão, como fronteira passível de apropriação e valorização do capital investido na compra de terras, como província mineral e/ou como fronteira agropecuária.

Segundo Serra e Fernandez (2004) o início dos anos 90 marcou um novo olhar sobre a Amazônia no sentido de conter a perca da floresta por atividades antropogênicas. Entre os principais eventos que influenciaram este processo, os autores destacam a constatação dos impactos negativos em termos sociais e ambientais do programa POLONOROESTE, que levaram à interrupção dos empréstimos concedidos, em 1985, pelo Banco Mundial; o assassinato do líder do movimento dos seringueiros, Chico Mendes, em dezembro de 1988, fato que transformou um conflito local totalmente ignorado em um acontecimento internacional; os protestos das populações indígenas contra a construção de duas represas no rio Xingu, mostrando claramente 0 crescente descontentamento com 0 processo de tomada de decisão unilateral nos programas de desenvolvimento; os vários confrontos entre as ONG's e o governo federal sobre as políticas governamentais para a região amazônica; e uma série de manifestações na sede do Banco Mundial em Washington.

Vale ressaltar que a pecuária é indicada como principal causa desse desmatamento ${ }^{2}$. Para Fearnside (2005) "embora a floresta amazônica seja desmatada por inúmeras razões, a criação de gado ainda é a causa predominante"; da mesma forma Margulis (2003) diz "a pecuária é a principal atividade econômica na região e são os médios e grandes pecuaristas os maiores responsáveis pelos desmatamentos".

Até meados da década de 90 o Brasil tinha parcela significativa no mercado mundial de carne bovina, mas enfrentava dificuldades para expandir sua participação em função de problemas sanitários (febre aftosa no rebanho) que implicavam em barreiras não-tarifárias ${ }^{3}$ pelos mercados importadores. Por exemplo, a Austrália em 1992, com uma produção correspondente a $4,02 \%$ da produção mundial, participava com $23,75 \%$ do total mundial exportado. Já o Brasil, com uma participação na produção mundial de 9,67\%, participava com apenas $8,65 \%$ das exportações mundiais de carne bovina (USDA, 2009). O Brasil participava principalmente com as exportações de produtos cárneos industrializados, para qual não há tantas restrições sanitárias como para os cortes in natura.

Assim, para tornar-se líder três elementos foram fundamentais para inserção

2 O Instituto Nacional de Pesquisas Espaciais (INPE) considera desmatamento a conversão de áreas de floresta primária por atividades antropogênicas para o desenvolvimento de atividades agropecuárias. Deste modo, as áreas em processo de sucessão secundária são excluídas do cálculo dos desmatamentos brutos totais e anuais, implicando que uma área uma vez desflorestada assim será considerada permanentemente.

${ }^{3}$ O comércio internacional, não é um mercado completamente livre para as trocas comerciais. Diversas são as formas de restrições que podem ser impostas a no que diz respeito ao fluxo internacional de mercadorias. Destacam-se nesse sentido as Barreiras Não-Tarifárias, modalidade mais comum de ação restritiva ao comércio internacional entre os países, já que as mesmas não podem ser mensuradas, e referem-se a obstáculos resultantes de regulamentações para o comércio internacional e englobam medidas sanitárias e fitossanitárias.

Revista de Estudos Sociais - Ano 2013, Nro 29, Vol 15 Pag. 80 
soberana do país nesse comércio. Um deles corresponde às ações direcionadas pelo Governo Federal, através do Ministério da Agricultura, Pecuária e Abastecimento 4 (MAPA) visando reestruturar a cadeia produtiva de carne bovina. Essa cadeia é formada pela indústria de insumos; pecuaristas; indústrias de abate e de preparação da carne; distribuidores (atacadistas e varejistas); e consumidor final; sendo a espinha dorsal constituída pelos pecuaristas, indústria frigorífica e varejista (WILKINSON e ROCHA, 2005). As ações estiveram direcionadas para os elos: pecuária e indústria frigorífica.

Entre as principais medidas se destacam o Programa de Erradicação da Febre Aftosa (PNEFA) e as Portarias 304 e 145. O PNEFA teve início em 1992 e obteve o primeiro resultado em 1998 com o reconhecimento da primeira área livre de febre aftosa com vacinação nos estados do Rio Grande do Sul e Santa Catarina. A certificação de área livre de febre aftosa tem reconhecimento internacional com o aval da Organização Internacional de Epizootias (OIE).

As medidas adotadas a partir das Portarias 304 e 145 introduziram modificações racionais e progressivas para se alcançar avanços em termos higiênicos, sanitários e tecnológicos na distribuição e comercialização de carne bovina, bubalina e suína. Essas portarias também tiveram, por princípio, a reorganização de toda a cadeia agroindustrial da pecuária de corte no Brasil (IEL, 2000).

$O$ segundo elemento corresponde às transformações no mercado mundial de carne bovina nas duas últimas décadas. A incidência na Europa da encefalopatia espongiforme bovina (BSE), popularmente conhecida como "doença da vaca louca"; o foco de febre aftosa em 2002 e o caso confirmado da "vaca louca" nos Estados Unidos e no Canadá em 2003; a seca australiana; e os problemas de febre aftosa no rebanho da Argentina; foram alguns dos fatores que contribuíram para mudanças significativas. Fatos de ordem sanitária desembocam frequentemente em embargos às exportações; na redução do consumo em função do medo de novas doenças, por parte dos consumidores; e, em sacrifício de rebanhos, o que, dependendo da dimensão, implicará na redução da oferta de matéria-prima.

$O$ terceiro elemento diz respeito a capacidade produtiva e concorrencial da carne bovina brasileira. 0 rebanho brasileiro destaca-se aproximadamente desde 1990 como o segundo maior rebanho mundial. 0 país estava entre os 10 maiores produtores mundiais de carne bovina desde o início da década de 90. Em 1994 o Brasil era o quinto exportador mundial de carne bovina. Assim, mesmo apresentando capacidade de produção o país não superava, por exemplo, as exportações da Austrália em função de não atender critérios do mercado consumidor internacional como estar livre da febre aftosa e pela produtividade de

${ }^{4}$ A partir de 2001 através da Medida Provisória 2216-37 de 31 de agosto de 2001 o Ministério da Agricultura e Abastecimento incorporou em seu nome a designação pecuária, passando a ser denominado Ministério da Agricultura, Pecuária e Abastecimento. Esta ação se deu em função da clara demonstração da importância deste segmento pelo destaque do agronegócio de carnes no mercado brasileiro, bem como no mercado global (BRASIL, 2009a).

Revista de Estudos Sociais - Ano 2013, Nro 29, Vol 15 Pag. 81 
algumas áreas exportadoras como Austrália, EUA e União Europeia.

Em relação a competitividade, com vantagens proporcionadas pela abundância e qualidade de recursos naturais o Brasil concorre no mercado internacional de commodities, com menores custos de produção. Segundo Pineda (2000 apud NEVES et al. 2000) no Brasil os custos de produção são em média $50 \%$ inferiores aos de outros grandes exportadores de carne bovina, como os Estados Unidos e a Austrália. Esta vantagem pode ser caracterizada pelo que Bain (1956 apud POSSAS, 1990, p. 95) chama de vantagens absolutas de custos, que são "atribuídas ao controle de métodos de produção (com ou sem patentes), insumos, equipamentos, tipos de qualificação do trabalho, capacidade empresarial etc., inclusive vantagens monetárias - em preços favorecidos ou crédito mais barato e/ou acessível". Outro fator diz respeito à alimentação do rebanho brasileiro. 0 governo federal proibiu a utilização de ração elaborada com tecidos de ruminantes na alimentação de ruminantes, pois este tipo de alimentação pode provocar a doença da vaca louca.

Os três elementos reorganização da cadeia produtiva, transformações no mercado internacional e capacidade produtiva e concorrencial deram a tônica para o Brasil iniciar um processo de expansão em suas exportações de carne bovina no fim da década de 90 e assim tornar-se o líder nesse mercado. A parte a capacidade produtiva e concorrencial, que acompanham a pecuária brasileira, os outros dois elementos passam a se coadunar durante a década de 90 .

Os problemas sanitários que ocorreram nos rebanhos bovinos de grandes exportadores como União Européia, Argentina, EUA geraram um nicho de mercado para outros exportadores na década de 90 , somou-se, assim, ao processo de reorganização da cadeia produtiva de carne bovina, e a uma política cambial que passava a favorecer as exportações a partir de 1999.

Esse fenômeno exigirá da indústria frigorífica atendimento desse mercado consumidor com matéria-prima de qualidade. As exportações de carne bovina brasileira tinham como origem a produção de São Paulo, Minas Gerais, Rio Grande do Sul, Goiás e Mato Grosso do Sul. Esses estados constituem a área onde a indústria frigorífica primeiro se instala no início do século XX. As empresas aí localizadas vão atender a expansão das exportações brasileiras. No entanto, o consumo brasileiro de carne bovina corresponde ao terceiro consumo mundial e, portanto, expandir as exportações implicava em não desconsiderar o mercado interno.

A partir desse momento a capacidade produtiva da Amazônia começa a se destacar no cenário da pecuária brasileira no atendimento do consumo interno e pela inserção nas exportações brasileiras de carne bovina. A chegada do grande capital agroindustrial na Amazônia expressa sua inserção nesta dinâmica. Este trabalho trata das novas relações entre a pecuária na Amazônia e as empresas líderes da indústria frigorífica de exportação brasileira. Esta configuração é recente nos estados da Amazônia. Para essas grandes empresas o fornecimento de matéria prima de qualidade com preço baixo é fator de 
competitividade, pois não basta ter o recurso, mas esse recurso precisa ser competitivo.

Em grande parte detentoras de processos de certificação para exportação, essas empresas chegam a região com tecnologia semelhante à utilizada nas plantas de origem em suas plantas de origem. Em contrapartida, a Amazônia apresenta capacidade produtiva, competitiva e de qualidade de matéria prima para atender a agroindústria de exportação. A chegada dessa agroindústria esta intrinsecamente ligada a capacidade da região em atender essas empresas com matéria prima semelhante a de outros estados exportadores.

A Amazônia Legal Brasileira é formada pelos estados do Acre, Amapá, Amazonas, Mato Grosso, Pará, Rondônia, Roraima, Tocantins e parte do Maranhão (oeste do meridiano de $44^{\circ}$ ). $O$ fenômeno em análise pode ser visto em uma parte da Amazônia, onde podemos encontrar a interligação entre pecuária e grande capital agroindustrial. Nos estados de Mato Grosso, Tocantins, Rondônia, Pará e Acre encontra-se instalando plantas frigoríficas de exportação. Assim, faz-se relevante compreender como a pecuária é inserida na Amazônia e como ocorre seu processo de expansão e consolidação, que irá proporcionar capacidade produtiva para contribuir com o destaque do Brasil no mercado internacional de carne bovina.

\section{A PECUÁRIA INCENTIVADA}

Velho (1972, p. 93) coloca que "há uma tendência a identificar o início do surgimento econômico da Amazônia como a construção da Belém-Brasília, os incentivos fiscais, a criação da Superintendência do Desenvolvimento da Amazônia (SUDAM) etc.". A pecuária da Amazônia é em grande parte associada a este período, mas como o mesmo autor ressalta "apesar do peso crescente das iniciativas do Estado no processo de desenvolvimento, o fato é que elas só se tornam em geral viáveis quando carregadas do senso de aproveitamento de determinados movimentos sociais" (VELHO, 1972, p. 93).

Neste sentido que não se pode desconsiderar um movimento dinâmico dessa atividade que pôde ser aproveitado para a dinâmica de planejamento daquele momento que constitui a fase de intervenção estatal ${ }^{5}$ mais expressiva na Amazônia. Nesse período a região é inserida em um contexto de planejamento nacional definido segundo estratégias do Estado

\footnotetext{
${ }^{5}$ Entre as primeiras tentativas de planejamento para região amazônica destacam-se "o Plano de Defesa da Borracha" em 1912, e a "Batalha da Borracha", em 1942, ambas em função da dependência econômica que se estabeleceu na região em relação a extração da borracha. Pela Constituição de 1946, "o artigo 199 dispôs sobre o estabelecimento de um programa de desenvolvimento para a Amazônia, a ser financiado por uma parcela de $3 \%$ do total das receitas de impostos federais durante um prazo de vinte anos consecutivos. Além disso, os governos estaduais e municipais da região contribuiriam para esse fim com parcela idêntica de suas receitas" (MAHAR, 1978, p. 15). No entanto, somente em 1953, através da Lei no 1806 o artigo 199 da Constituição de 1946 foi regulamentado, criando Plano de valorização econômica da Amazônia, que visava diversificar e desenvolver a produção agrícola, mineral e industrial da região. Também foi criado, neste ano, um órgão para administrar esse plano, a Superintendência do Plano de Valorização Econômica da Amazônia (SPVEA). Mas, somente a partir da entrada do governo militar o Estado efetivamente passou a atuar e provocar mudanças significativas na estrutura regional amazônica.
}

Revista de Estudos Sociais - Ano 2013, Nro 29, Vol 15 Pag. 83 
que pode ser assim descrita:

[...] o Brasil foi capaz de, a partir de 1964, por obra da política global entronizada pela Revolução daquele ano, retificar seus cursos de ação e escolher uma estratégia de desenvolvimento bem diversa do modelo que presidiu a industrialização dos anos 50. Enquanto o padrão de substituição de importação tivera inspiração introspectiva, de concentração sobre o mercado interno com relativo alheamento do mundo exterior, a política de desenvolvimento da fase revolucionária é deliberadamente calcada numa abertura para a economia mundial. [...] 0 período 1967/71, após a fase de recuperação de 1964/66, não se recomenda apenas pelo excepcional desempenho marcado por uma taxa média anual de crescimento do PIB superior a $8,5 \%$, mas, sobretudo por uma modernização de aparelho produtivo e pelo aprimoramento institucional e de estruturas que garantem a construção de uma sociedade progressista, em bases duradouras (QUEIROZ, 1974, p. 78-92 apud IANNI, 1986, p. 2022).

Inaugurou-se uma fase do planejamento da economia brasileira, baseada na intervenção do Estado, que se utiliza da interpretação cepalina ${ }^{6}$ sobre a condição de um país periférico, mas estabelece uma nova estratégia para deixar essa condição, baseado na modernização do setor produtivo do país através da substituição de importações, mas com a produção nacional voltada para o mercado externo. Para tanto, o capital monopolista vai ser a base dos investimentos, a base de recursos do qual o Estado lançara mão para promover essa modernização.

A Amazônia será inserida em um primeiro momento num desdobramento deste modelo a nível regional. "Esse modelo envolvia fundamentalmente a promoção da industrialização via substituição de importações, financiado por capital externo e interno" (MAHAR, 1978, p. 22). Este era o aspecto da política econômica para Amazônia. 0 aspecto geopolítico, outro princípio norteador da política regional "estava implícito naqueles objetivos que pediam a efetiva ocupação da região através da imigração inter-regional e estrangeira e a formação de assentamentos permanentes e auto-suficientes nas áreas de fronteira"

${ }^{6} \mathrm{Na}$ década de quarenta, começava a se formar na América Latina a escola estruturalista latino-americana, também conhecida como Comissão Econômica para a América Latina e o Caribe (CEPAL), que viria a influenciar através de suas análises, a condução da política econômica brasileira até o início da década de 1970. A CEPAL conclui, que as economias periféricas, se deixadas sob o comando da mão invisível, nunca deixariam de ser agroexportadoras e, o Estado deveria intervir na promoção da industrialização, que elevaria estes da condição de periferia à condição de centro.

Revista de Estudos Sociais - Ano 2013, Nro 29, Vol 15 Pag. 84 
(MAHAR, 1978, p. 22). Mas, a Amazônia, não se encaixava no aspecto econômico, tendo em vista a desigualdade de formação econômica regional brasileira. A política de modernização, a nível nacional, vai se apoderar de setores no qual havia uma pré-disposição para a modernização.

No geral as políticas regionais da ditadura seguirão dois caminhos. "Por um lado, principalmente nas atividades agrícolas localizadas no Centro-Sul, o Estado foi levado a favorecer o desenvolvimento intensivo do capitalismo. Por outro lado, [...] na Amazônia, o Estado foi levado a favorecer o desenvolvimento extensivo do capitalismo" (IANNI, 1986, p. 16).

De uma forma mais clara, a política regional vai se orientar pelo Artigo $4 .{ }^{\circ}$ da Lei $n^{\circ}$ 5.173, de 27 de outubro de 1966, para formação de pólos de desenvolvimento, ocupação da região, fluxo migratório para Amazônia, incentivos ao capital privado e desenvolvimento da infra-estrutura. Vão se constituir como principais instrumentos dessa política a Superintendência do Desenvolvimento da Amazônia (SUDAM), criada em 1966; e, o Banco da Amazônia S.A (BASA), também criado em 1966. Para operacionalizar essa política formulou-se em 1967 o I Plano quinquenal de desenvolvimento da SUDAM, no qual segundo Mahar (1978), todos os objetivos conformavam-se em geral ao modelo econômico de substituição de importações pela região e aos imperativos geopolíticos de ocupação humana.

No entanto, no início da década de 1970 iniciativas como a criação do Programa de Integração Nacional (PIN) e do Programa de Redistribuição de Terras e de Estímulo à Agroindústria do Norte e do Nordeste (PROTERRA) implicaram uma nova direção a política regional da Amazônia, no sentido de estabelecer prioridades de investimentos em atividades agrícolas em detrimento da indústria. Isto se faz, de acordo com os próprios objetivos desses programas, uma vez que o PIN é criado para promover a integração da Amazônia e da região nordeste com o restante do Brasil através da construção das rodovias Transamazônica e Cuiabá-Santarém, e a execução de um plano de irrigação do Nordeste. O PROTERRA é criado com o objetivo de promover o mais fácil acesso do homem à terra, criar melhores condições de emprego de mão-de-obra e fomentar a agroindústria nas regiões compreendidas nas áreas de atuação da SUDAM e da Superintendência do Desenvolvimento do Nordeste (SUDENE).

$O$ desenvolvimento da Amazônia, assim, esteve intimamente ligado naquele momento ao projeto nacional de Desenvolvimento. O I Plano Nacional de Desenvolvimento (PND), refletiu-se no I Plano de desenvolvimento da Amazônia (PDAm), no período 1972-74, e neste plano estava implícito que a agricultura e a pecuária receberiam as mais altas prioridades. Posteriormente formulou-se, para o período 1975-79 o II PND, e, conjuntamente o II PDAm. "Pelas referências específicas à Amazônia no II PND tem-se a impressão de que as autoridades decidiram afinal que essa região é realmente uma "fronteira de recursos" (portanto, um grande bem nacional) e não uma típica região deprimida"(MAHAR, 1978, p. 44). 
Nesse sentido que a pecuária tornou uma das atividades privilegiadas pelo Governo para atender a política de ocupação da região. A partir da década de 60 , a expansão para Amazônia estimulada por incentivos governamentais, abertura de rodovias e farta distribuição de terras, a bovinocultura abre nova frente de expansão. A derrubada e queimada do mato para o surgimento da pastagem e posterior ocupação com bovinos eram a forma mais rápida, de menor esforço administrativo e mais eficiente para assegurar a posse da terra. Some-se a isso o fato de poder ser usada como justificativa para acesso aos estímulos governamentais, tais como incentivos fiscais e creditícios subsidiados, para que a bovinocultura se propagasse para região.

Segundo Silva (1982) a pecuária pode ser vista como uma expressão histórica de ocupação da fronteira. Em um sentindo de ocupação das terras como reserva de valor, inicialmente. Não é a ocupação efetiva do solo no sentido de fazê-lo produzir, mas sim uma "ocupação pela pecuária" com finalidade precípua de garantir a propriedade privada daquela terra. É essa perspectiva que a pecuária assume na Amazônia nesse período. De acordo com Costa (2000),

A pecuária de grande porte mostrava-se, assim, duplamente positiva: poderia adequar o uso de grandes extensões de terras com um mínimo de trabalhadores e tolher a expansão da agricultura tradicional de terras novas (a expansão da fronteira agrícola), garantindo mercado para a intensificação da produção de arroz, milho, feijão e mandioca em áreas antigas. A grande plantation poderia cumprir parte da tarefa, sendo limitada, contudo, por ser trabalho-intensiva. Conformou-se, a partir daí, a política de incentivos fiscais que, em conjunto com uma política de terras favorecedoras das grandes apropriações, imprimiu características próprias à fronteira agrícola na Amazônia a partir da segunda metade dos anos 60 (COSTA, 2000, p. 83, grifo do autor).

Mahar (1978) descreve dois modelos de pecuária praticados na Amazônia, antes dos projetos da SUDAM. O superextensivo tradicional praticado no Amapá, Roraima, Amazonas o nordeste do Pará, e caracterizado por ser praticado em áreas desfavoráveis a pecuária, mas que sobrevivia devido a demanda por carne nos mercados de Belém e Manaus. O segundo modelo, extensivo tradicional, praticado no Acre, Rondônia, centro e norte do Pará, e partes do nordeste de Mato Grosso e Goiás, caracterizado como uma região um pouco mais receptiva a formação de pastagens artificiais e criação do gado em zonas ecologicamente favoráveis.

[...] a maior parte dos projetos da SUDAM recai numa terceira categoria, conhecida como modelo "extensivo-modernizador". As fazendas que adotam este método de produção encontram-

Revista de Estudos Sociais - Ano 2013, Nro 29, Vol 15 Pag. 86 
se em geral no leste e sudeste do Pará, norte de Mato Grosso e Goiás, e oeste do Maranhão (microrregião de Imperatriz). Localizam-se em áreas essencialmente favoráveis à pecuária e tendem a especializar-se na produção de carne. Os tipos de gado usados são muito superiores aos observados nos dois outros modelos, predominando raças indianas, como Gir e Nelore (MAHAR, 1978, p. 146).

Para o desenvolvimento da atividade, o principal instrumento era a Lei $n .{ }^{\circ} 5.174$ que admitia que pessoas jurídicas brasileiras poderiam descontar até $50 \%$ do imposto de renda devido desde que as poupanças resultantes fossem investidas em projetos localizados dentro da "Amazônia Legal" e aprovados pela SUDAM. Os projetos de investimentos poderiam destinar-se tanto a criação de empresas novas como representar simplesmente expansão e/ou modernização de empresas existentes; ou destinar-se à agricultura, pecuária, indústria e serviços (MAHAR, 1978). "Exigia-se, por outro lado, que os titulares de projeto candidato aos incentivos fiscais participassem com no mínimo $25 \%$ da previsão de investimentos na forma de capital próprio - era previsto, assim, que até $75 \%$ dos investimentos pudessem vir a ser cobertos por recursos dos incentivos fiscais" (COSTA, 2000, p. 53-54).

Para Mahar (1978) os resultados provisórios dos programas iniciados no início da década de 1970, mostraram que projetos pecuários intensivos em terras foram preferidos na região amazônica, sendo que "entre 1964 e meados de 1976, a SUDAM aprovou mais de 800 projetos de fundos de crédito fiscal, sendo: 329 industriais, 462 pecuários e 27 em serviços básicos". O motivo, segundo Mahar (1978) seriam que na Amazônia, as vantagens econômicas do investimento em pecuária (em oposição a indústria) são óbvias: existência de terra abundante e barata capaz de produzir rápidos ganhos de capital; requisitos mínimos de pessoal; e um mercado em expansão.

Mahar (1978) apresenta que cerca de 90\% do investimento projetado total no setor pecuário situavam-se nos estados de Mato Grosso e Pará, cabendo ao primeiro mais de $60 \%$ desses investimentos. À parte a existência de terra barata e abundante, as preferências locacionais dos proprietários de projetos pecuários têm sido influenciadas antes de tudo pelos novos sistemas rodoviários inter-regionais. Daí porque encontramos no Pará os projetos concentrados nas regiões leste e sudeste do estado, em microrregiões (principalmente Araguaia Paraense, Guajarina, Xingu e Marabá) adjacentes as estradas Belém-Brasília e Transamazônica. A influência do primeiro sistema rodoviário citado se observa também na distribuição espacial de projetos em Goiás e Maranhão. Os projetos de Mato Grosso, por sua vez, agrupam-se principalmente no eixo da recém inaugurada rodovia Santarém-Cuiabá, que proporciona acesso aos mercados das duas cidades e ainda aos de Brasília e Centro-Sul.

Revista de Estudos Sociais - Ano 2013, Nro 29, Vol 15 Pag. 87 


\section{DESLOCAMENTO DA PRODUÇÃO PECUÁRIA PARA AMAZÔNIA}

A partir do fim da década de 80 a região amazônica passou a comportar uma pecuária que se deslocava das regiões Sul e Sudeste a procura de terras mais baratas. Assim, um segundo momento que se sobrepõe na pecuária amazônica é o que se convencionou chamar de "deslocamento da produção pecuária". Para Diniz (2002), a produção agropecuária brasileira passou, e passa, por três grandes movimentos: deslocamento da produção agropecuária extensiva; intensificação produtiva nas regiões mais desenvolvidas; e crescimento nas áreas irrigadas do Nordeste. Segundo o Autor, o deslocamento da produção agropecuária extensiva diz respeito ao movimento de deslocamento da fronteira agrícola e pecuária das regiões Sudeste e Sul para regiões CentroOeste e Norte. Esse movimento indica o afastamento da produção agrícola extensiva e mecanizada para regiões com menor preço das terras e, adequadas para agricultura mecanizada.

Em contrapartida, nas antigas regiões de produção agrícola e pecuária extensiva, toma forma a intensificação produtiva em atividades mais rentáveis. As alterações da estrutura da produção agrícola, por exemplo, de São Paulo, com o crescimento da produção de cana-de-açúcar e laranja, além de horticultura e fruticultura, indicam uma reorientação da produção.

Esse deslocamento é caracterizado pelo processo de expansão mais acentuado nas áreas de pastagens e crescimento do rebanho nas regiões Centro Oeste e Norte em contrapartida da estabilização que se verifica nas regiões Sul e Sudeste. Na Tabela 2 observa-se que em 1940, a região Norte contribuía com 2,91\% do rebanho brasileiro, enquanto a região Sudeste tinha contribuição de $34,77 \%$, seguido pela região Sul com $25,2 \%$, a região Nordeste com 22,29\%, e a Centro Oeste $14,87 \%$.

O salto no rebanho da região Norte é observado entre 1975-1985, quando a região passa de 3.989 no primeiro ano para 8.966 milhões de bovinos em 1985. Assim, evolui de uma participação no rebanho nacional de 3,38\% em 1980 para 7\% em 1985. Em 20060 estado participava com $18,38 \%$ do rebanho nacional.

A região Centro Oeste assim como a região Norte apresenta crescimento ascendente na participação da composição do rebanho nacional, sendo que evoluiu de uma participação de $14,87 \%$ do rebanho brasileiro em 1940 uma participação de 31,64\% em 2006. A região Sudeste teve maior participação em 1960, correspondendo a $37,34 \%$ do rebanho nacional, no entanto, em 2006 , reduz sua participação para $20,6 \%$. A região Sul também diminui sua participação de $25,2 \%$, em 1940, para 14,06\%, em 2006.

Nesse sentido que autores como Diniz (2002) caracterizam o deslocamento da produção pecuária para regiões que ofereçam menores custos de produção, pois nas áreas antigas se estabilizam os rebanhos, assim a pecuária torna-se mais intensiva, com aumento 
de confinamentos, e a atividade precisa ser rentável para concorrer pelo uso do solo com outras culturas.

Tabela 1 - Concentração do rebanho bovino (cabeças), e participação percentual (\%), Brasil e Regiões, 1940/2006.

\begin{tabular}{lcccccccc}
\hline $\begin{array}{l}\text { Efetivo Bovino (Mil } \\
\text { cabeças) }\end{array}$ & 1940 & 1960 & 1970 & 1975 & 1980 & 1985 & 1995 & 2006 \\
\hline Norte & 999 & 1.235 & 1.706 & 2.130 & 3.989 & 8.966 & 17.277 & 31.234 \\
Centro Oeste & 5.112 & 10.533 & 17.252 & 24.750 & 33.261 & 36.116 & 50.767 & 53.750 \\
Sudeste & 11.957 & 20.849 & 26.845 & 35.237 & 34.835 & 35.742 & 35.954 & 34.994 \\
Sul & 8.664 & 11.678 & 18.953 & 21.516 & 24.495 & 24.827 & 26.220 & 23.889 \\
Nordeste & 7.665 & 11.566 & 13.806 & 18.041 & 21.506 & 22.391 & 22.842 & 26.033 \\
\hline Brasil & 34.387 & 55.841 & 78.562 & 101.674 & 118.086 & 128.042 & 153.058 & 169.900 \\
\hline \hline Participação & 1940 & 1960 & 1970 & 1975 & 1980 & 1985 & 1995 & 2006 \\
Percentual (\%) & 2,91 & 2,21 & 2,17 & 2,09 & 3,38 & 7,00 & 11,29 & 18,38 \\
\hline Norte & 14,87 & 18,86 & 21,96 & 24,34 & 28,17 & 28,21 & 33,17 & 31,64 \\
Centro Oeste & 34,77 & 37,34 & 34,17 & 34,66 & 29,50 & 27,91 & 23,49 & 20,60 \\
Sudeste & 25,20 & 20,91 & 24,12 & 21,16 & 20,74 & 19,39 & 17,13 & 14,06 \\
Sul & 22,29 & 20,71 & 17,57 & 17,74 & 18,21 & 17,49 & 14,92 & 15,32 \\
\hline Nordeste & 100,00 & 100,00 & 100,00 & 100,00 & 100,00 & 100,00 & 100,00 & 100,00 \\
\hline Brasil & 10,00
\end{tabular}

Fonte: Elaborado a partir de Perez (2003) e IBGE (2009).

Segundo Jank (1996) a pecuária de corte se depara com processos rápidos de melhoria de produto e processo, principalmente nas regiões onde a terra vai se tornado mais cara. Nestas regiões (São Paulo, sul do Mato Grosso Sul e Paraná), qualquer simples cálculo de retorno sobre o patrimônio mostrará a crescente inviabilização dos sistemas de cria e engorda extensiva, principalmente em face do custo de oportunidade de atividades como a cana-de-açúcar e a citricultura. Não é para menos, pois nestas regiões vem se desenvolvendo um número crescente de confinamento e semi-confinamento de bovinos.

Para Fürstenau (1995) a diminuição da área de pecuária observada nos Estados de São Paulo e Rio Grande do Sul teve dois efeitos simultâneos, de um lado, deslocou a produção pecuária para os estados vizinhos e, de outro, aumentou os índices de lotação por área nesses dois estados, gerando, portanto, aumentos da produtividade física da terra.

A estabilização nos rebanhos das regiões Sul e Sudeste foi reflexo da estabilização da expansão nas áreas de pastagens, e ao contrário nas regiões onde se verifica a expansão 
no rebanho ocorre expansão nas áreas de pastagens. A região Norte, assim como no efetivo bovino, apresentou crescimento acentuado na utilização das terras com pastagens. Em 1970 estas pastagens correspondiam a 2,87\% das áreas de pastagens no Brasil, cifra que em 2006, aumentou para 18,93\%. O aumento maior é verificado entre 1980 e 1985, pois no primeiro ano, correspondia a 4,43\%, e em 1985, saltou para $11,65 \%$.

A região Sudeste, reduziu a ocupação de terras com pastagens de $29,03 \%$, em 1970, para $18,61 \%$, em 2006 . Igualmente, a região Sul representava $14,03 \%$ das áreas de pastagens do Brasil em 1970, reduz sua participação para 10,53\% em 2006. A região Nordeste tem participação estável nas pastagens do país, em 1970 a participação era de $18,08 \%$ e em 2006 de $18,95 \%$.

Tabela 2 - Terras utilizadas com pastagens (ha), e participação percentual (\%), Brasil e Regiões, 1970/2006.

\begin{tabular}{|c|c|c|c|c|c|c|}
\hline $\begin{array}{l}\text { Pastagem } \\
\text { (ha) }\end{array}$ & 1970 & 1975 & 1980 & 1985 & 1995 & 2006 \\
\hline Norte & 4.428 .116 & 5.281 .440 & 7.722 .487 & 20.876 .442 & 24.386 .621 & 32.630 .532 \\
\hline Nordeste & 27.875 .111 & 30.624 .044 & 34.158 .706 & 35.148 .125 & 32.076 .339 & 32.648 .537 \\
\hline Sudeste & 44.739 .276 & 47.276 .785 & 43.639 .266 & 42.487.399 & 37.777 .049 & 32.071 .529 \\
\hline $\begin{array}{l}\text { Sul } \\
\text { Centro- } \\
\text { oeste }\end{array}$ & $\begin{array}{r}21.621 .679 \\
55.483 .348 \\
\end{array}$ & $\begin{array}{l}21.159 .758 \\
61.310 .221 \\
\end{array}$ & $\begin{array}{l}21.313 .458 \\
67.665 .720 \\
\end{array}$ & $\begin{array}{l}21.432 .343 \\
59.244 .117\end{array}$ & $\begin{array}{r}20.696 .549 \\
62.763 .912 \\
\end{array}$ & $\begin{array}{l}18.145 .573 \\
56.836 .902 \\
\end{array}$ \\
\hline Brasil & 154.138.529 & 165.652 .250 & 174.499.641 & 179.188.431 & 177.700 .472 & 172.333 .073 \\
\hline $\begin{array}{l}\text { Pastagem } \\
(\%)\end{array}$ & 1970 & 1975 & 1980 & 1985 & 1995 & 2006 \\
\hline Norte & 2,87 & 3,19 & 4,43 & 11,65 & 13,72 & 18,93 \\
\hline Nordeste & 18,08 & 18,49 & 19,58 & 19,62 & 18,05 & 18,95 \\
\hline Sudeste & 29,03 & 28,54 & 25,01 & 23,71 & 21,26 & 18,61 \\
\hline $\begin{array}{l}\text { Sul } \\
\text { Centro- } \\
\text { oeste }\end{array}$ & $\begin{array}{l}14,03 \\
36,00 \\
\end{array}$ & 12,77 & 12,21 & 11,96 & 11,65 & 10,53 \\
\hline Brasil & 100,00 & 100,00 & 100,00 & 100,00 & 100,00 & 100,00 \\
\hline
\end{tabular}

Fonte: Elaborado a partir do IBGE (2009).

A região Centro Oeste ocupava $36 \%$ das terras utilizadas com pastagens no país em 1970 , chegando a ocupar $38,75 \%$ em 1985 , cifra que se reduziu para $33,06 \%$ em 1985 , e em 2006 a ocupação correspondia a 32,98\%. Essa região corresponde a maior parte da 
ocupação de terras com pastagens no Brasil no período analisado, e a região Sul que tinha a terceira maior participação (14,03\%) em 1970, em 2006 passa a corresponder a menor área de pastagens entre as regiões brasileiras (10,53\%). Esses dados evidenciam que nas regiões Sudeste e Sul tem se reduzido á área destinada a pastagens, e isso pode ser explicado pela intensificação da atividade e pela substituição de pastagens por outras culturas mais rentáveis, como nos coloca Diniz (2002).

$\mathrm{Na}$ Tabela 4 apresenta-se as duas principais ocupações econômicas das terras, lavouras e pastagens, para corroborar o processo que descrevemos de substituição de lavouras por pastagens em algumas regiões do país que implica na expansão das pastagens em outras áreas. No Brasil a ocupação das terras com lavouras aumentou 10,38\%, enquanto a área para pastagens reduziu 1,35\%. A substituição de lavouras por pastagens tem sido observado nos estados de São Paulo, que apresenta uma redução de 14,67\% nas áreas de pastagens e um aumento de 6,55\% a.a. na utilização de terras com lavouras; Rio Grande do Sul apresenta redução de $12,03 \%$ a.a. nas áreas de pastagens e aumento de 3,05\% a.a. nas áreas com lavouras; 0 estado de Minas Gerais reduziu as pastagens em $16,85 \%$ a.a. nas terras ocupadas com pastagens e teve um incremento de $5,67 \%$ com terras ocupadas com lavouras.

Entre os estados da Amazônia, Tocantins apresentou redução na incorporação de áreas com pastagens e lavouras, no entanto, a área de pastagem reduziu $13,02 \%$ a.a. e área com lavoura $1,67 \%$ a.a. Alguns estados da região apresentam expansão nas áreas de pastagens e lavouras, mas com maior expansão nas áreas de pastagens, como Rondônia que aumentou as pastagens em $176,46 \%$ a.a, e lavouras $29,84 \%$ a.a; Acre apresentou expansão de $101,52 \%$ a.a. nas pastagens e $52,75 \%$ a.a. na área com lavoura; o estado do Pará incorporou $48,22 \%$ a.a. em áreas para pastagens e $30,29 \%$ a.a para lavouras. 0 estado de Mato Grosso apresentou menor incorporação de áreas para pastagens, $25,26 \%$ a.a., e maior incorporação de terras para lavouras, $121,03 \%$ a.a.

Esses dados evidenciam o caráter de expansão da pecuária amazônica em detrimento da intensificação da pecuária em outros estados e a substituição de culturas mais rentáveis pela pecuária. No entanto, vale destacar que Tocantins registrou redução maior na incorporação de áreas para pastagens em detrimento das áreas para lavouras e Mato Grosso teve maior expansão nas áreas de lavouras em detrimento das áreas de pastagens, demonstrando que nesses estados a pecuária tem se tornado mais intensiva para concorrer com atividades da agricultura mais rentáveis como soja e arroz.

Revista de Estudos Sociais - Ano 2013, Nro 29, Vol 15 Pag. 91 
Tabela 3 - Utilização das terras com lavouras e pastagens (ha), Brasil e estados selecionados, 1975/2006, e T.G.C. (\%), 1975/2006.

\begin{tabular}{|c|c|c|c|c|c|}
\hline $\begin{array}{l}\text { Utilização das } \\
\text { terras }\end{array}$ & 1975 & 1985 & 1995 & 2006 & T.G.C. \\
\hline & \multicolumn{4}{|c|}{ Brasil } & \\
\hline Lavouras & 40.001 .358 & 52.147 .708 & 41.794 .455 & 59.846 .618 & 10,38 \\
\hline \multirow[t]{2}{*}{ Pastagens } & 165.652 .250 & 179.188 .431 & 177.700 .472 & 158.753 .866 & $-1,35$ \\
\hline & \multicolumn{5}{|c|}{ Rondônia } \\
\hline Lavouras & 193.463 & 530.543 & 432.308 & 494.644 & 29,84 \\
\hline Pastagens & \multicolumn{4}{|c|}{ Acre } & 176,46 \\
\hline Lavouras & 41.187 & 68.719 & 75.939 & 163.526 & 52,75 \\
\hline \multirow[t]{2}{*}{ Pastagens } & 124.104 & 326.026 & 614.213 & 1.038 .725 & 101,52 \\
\hline & \multicolumn{4}{|c|}{ Pará } & \\
\hline Lavouras & 704.027 & 1.078 .630 & 808.354 & 1.872 .451 & 30,29 \\
\hline \multirow[t]{2}{*}{ Pastagens } & 3.037 .190 & 6.596 .393 & 7.455 .728 & 10.825 .118 & 48,22 \\
\hline & \multicolumn{4}{|c|}{ Tocantins } & \\
\hline Lavouras & - & 654.953 & 267.228 & 633.265 & $-1,67$ \\
\hline \multirow[t]{2}{*}{ Pastagens } & - & 10.650 .900 & 11.078 .156 & 8.057 .429 & $-13,02$ \\
\hline & \multicolumn{4}{|c|}{ Mato Grosso } & \\
\hline Lavouras & 501.267 & 2.129 .443 & 2.951 .745 & 6.323 .475 & 121,03 \\
\hline \multirow[t]{2}{*}{ Pastagens } & 11.243 .468 & 16.404 .370 & 21.452 .061 & 21.784 .735 & 25,26 \\
\hline & \multicolumn{4}{|c|}{ Amazonas } & \\
\hline Lavouras & 371.426 & 456.452 & 372.840 & 1.393 .564 & 45,71 \\
\hline Pastagens & \multicolumn{4}{|c|}{ Roraima } & 55,33 \\
\hline Lavouras & 27.098 & 27.830 & 133.012 & 114.274 & 80,07 \\
\hline \multirow[t]{2}{*}{ Pastagens } & 1.353 .168 & 1.247 .213 & 1.542 .565 & 719.653 & $-15,48$ \\
\hline & \multicolumn{4}{|c|}{ Amapá } & \\
\hline Lavouras & 25.061 & 33.270 & 19.853 & 62.153 & 24,71 \\
\hline \multirow[t]{2}{*}{ Pastagens } & 350.023 & 478.894 & 244.978 & 267.064 & $-13,77$ \\
\hline & \multicolumn{4}{|c|}{ Maranhão } & \\
\hline Lavouras & 1.055 .955 & 1.304 .509 & 821.827 & 2.448 .383 & 22,89 \\
\hline \multirow[t]{2}{*}{ Pastagens } & 3.808 .835 & 5.446 .563 & 5.310 .552 & 5.728 .628 & 12,74 \\
\hline & \multicolumn{4}{|c|}{ São Paulo } & \\
\hline Lavouras & 5.179 .506 & 6.524 .801 & 5.256 .168 & 6.876 .591 & 6,55 \\
\hline \multirow[t]{2}{*}{ Pastagens } & 11.355 .901 & 9.926 .490 & 9.062 .254 & 6.898 .987 & $-14,67$ \\
\hline & \multicolumn{4}{|c|}{ Rio Grande do Sul } & \\
\hline Lavouras & 5.929 .490 & 6.592 .085 & 5.635 .362 & 6.905 .582 & 3,05 \\
\hline \multirow[t]{2}{*}{ Pastagens } & 13.772 .888 & 12.963 .460 & 11.680 .328 & 9.206 .664 & $-12,3$ \\
\hline & \multicolumn{4}{|c|}{ Mato Grosso do Sul } & \\
\hline Lavouras & 1.274 .627 & 1.902 .970 & 1.383 .711 & 2.183 .833 & 13,84 \\
\hline \multirow[t]{2}{*}{ Pastagens } & 20.793 .497 & 21.802 .753 & 21.810 .708 & 20.943 .814 & 0,22 \\
\hline & \multicolumn{3}{|c|}{ Goiás } & & \\
\hline
\end{tabular}

Revista de Estudos Sociais - Ano 2013, Nro 29, Vol 15 Pag. 92 


\begin{tabular}{lrrrr|r} 
Lavouras & 2.561 .094 & 2.928 .199 & 2.174 .853 & 3.606 .740 & 7,57 \\
Pastagens & 29.164 .163 & 20.894 .584 & 19.404 .696 & 15.709 .871 & $-17,55$ \\
& \multicolumn{5}{c}{ Minas gerais } \\
Lavouras & 3.980 .821 & 5.340 .110 & 4.172 .135 & 5.194 .765 & 5,67 \\
Pastagens & 31.931 .282 & 28.924 .183 & 25.348 .603 & 18.039 .776 & $-16,85$ \\
\hline
\end{tabular}
Fonte: IBGE (2009).

O deslocamento da produção pecuária fez com que novas unidades de abate fossem instaladas, provocando até mesmo deslocamento de frigoríicos anteriormente instalados em outras regiões. Neste sentido, uma pesquisa realizada pelo IEL (2000) aponta que a opinião geral dos agentes envolvidos na cadeia produtiva de carne bovina é que se devem construir unidades localizadas perto das regiões produtoras de animais. Na Tabela 5 , apresentamos a evolução dos estabelecimentos registrados no SIF por região.

Tabela 4 - Estabelecimentos registrados no Sistema de Inspeção Federal por regiões (unidades) e participação percentual (\%), 1995/2006.

\begin{tabular}{|c|c|c|c|c|c|c|}
\hline \multirow[b]{2}{*}{ Regiões } & \multicolumn{2}{|c|}{1995} & \multicolumn{2}{|c|}{2000} & \multicolumn{2}{|c|}{2006} \\
\hline & $\mathrm{N}^{0}$ & $\%$ & $\mathrm{~N}^{\circ}$ & $\%$ & $\mathrm{~N}^{\circ}$ & $\%$ \\
\hline Norte & 13 & 4,22 & 26 & 8,39 & 31 & 8,81 \\
\hline Centro Oeste & 67 & 21,75 & 93 & 30,00 & 94 & 26,7 \\
\hline Sudeste & 125 & 40,58 & 99 & 31,94 & 106 & 30,11 \\
\hline Sul & 85 & 27,60 & 70 & 22,58 & 99 & 28,13 \\
\hline Nordeste & 18 & 5,85 & 22 & 7,10 & 22 & 6,25 \\
\hline Brasil & 308 & 100 & 310 & 100 & 352 & 100 \\
\hline
\end{tabular}

Fonte: Elaborado a partir de Santos et al. (2007).

Em termos de participação no total dos estabelecimentos brasileiros, percebe-se que o Centro Oeste, Sudeste e Sul correspondem a maior concentração desses estabelecimentos. A região Norte evoluiu de treze unidades instaladas em 1995, para trinta e uma, em 2006. A região Sudeste apresenta redução no número de estabelecimentos, entre 1995 e 2000. No primeiro ano havia cento e vinte cinco frigoríficos instalados na região; em 2000 , esse número de reduz para noventa e nove. No entanto, em 2006, esse número aumenta para cento e seis. Mas na participação total dos estabelecimentos brasileiros reduziu de $40,58 \%$, em 1995, para $30,11 \%$, no ano 2000 .

Assim, o crescimento do rebanho implicou no aprofundamento da agroindustrialização da região amazônica com deslocamento das unidades de abate de 
bovinos. As vantagens decorreram além da fartura de matéria-prima, dos preços inferiores aos negociados em São Paulo, da redução do custo do frete e da existência de linhas de crédito subsidiadas do Banco do Brasil e do BNDES. Alie-se, ademais, a eliminação do stress no transporte dos bovinos (MAZZALI, 2000).

Atualmente os estados de Mato Grosso, Rondônia, Tocantins, Acre e Sul do Pará são regiões livres de febre aftosa, o que proporciona uma grande vantagem para a agroindústria de exportação. No entanto, as exportações para União Europeia, principal mercado importador de carne bovina brasileira, são permitidas apenas para o estado de Mato Grosso entre os estados da Amazônia. Fato que pode ser explicado pela exigência de rastreabilidade, já que o estado é o único da região amazônica com estabelecimentos registrados no Serviço Brasileiro de Rastreabilidade da Cadeia Produtiva de Bovinos e Bubalinos (SISBOV).

\section{CONSIDERAÇÕES FINAIS}

O período da pecuária incentivada constitui um dos momentos que contribuem para expansão da pecuária na Amazônia. Nesse momento a atividade torna-se um instrumento de ocupação territorial em meio as estratégias intervencionistas de desenvolvimento regional do Estado entre as décadas de 60 e 80. Parte-se desse princípio, uma vez que a pecuária torna-se expressiva na região a partir desse momento em função dos incentivos fiscais que recebe e pelo caráter que assume de ocupação territorial.

A pecuária de corte no Brasil possui aptidão para ocupar áreas marginais e desenvolver-se em pastagens naturais, sendo, portanto, uma atividade desbravadora de novas áreas. Desse modo, pode ser deslocada para as regiões mais afastadas e menos desenvolvidas. A medida, porém, que essas regiões se desenvolvem, a valorização da terra exerce pressão a favor de atividades relativamente mais rentáveis, da agricultura, que passam a ocupar as áreas de pastagens, deslocando-as para áreas menos férteis ou para áreas desprovidas de infra-estrutura econômica.

Esse processo, se por um lado é responsável pelos pequenos incrementos observados na pecuária de corte nacional, por outro contribui para a melhoria do rebanho nacional e dos sistemas de produção que permanecem competindo pela ocupação das terras mais valorizadas. Deste fato decorre a existência de diferentes sistemas de produção com pecuaristas, de um lado, mais intensivos e com maior produtividade e, de outro lado, pecuaristas menos intensivos e menos produtivos.

O aumento da capacidade instalada tem demonstrado a evolução da pecuária amazônica. Estados importantes da dinâmica nacional da cadeia produtiva de carne bovina tem se mantido estável em relação a produção e abate. Mesmo com aumento de processos de confinamento e produtividade, a expansão do rebanho é determinante para expansão da 
capacidade produtiva da indústria frigorífica. Na Amazônia, esse processo interage em função da expansão descontrolada na região, onde a ocupação ainda é realizada de forma ilegal e dá suporte para o crescimento do rebanho. Já em estados como São Paulo, a pecuária precisa concorrer com outras culturas rentáveis e, portanto, a ocupação de grandes extensões para uma pecuária extensiva tem se reduzido.

A chegada da agroindústria pressupõe uma pecuária apta a atender aspectos qualitativos e sanitários, portanto, que houve uma modernização técnica, com incorporação de tecnologias em um estrato da pecuária amazônica. E, essa chegada implica em uma expansão dessa modernização no setor pecuarista introduzindo normas sanitárias e de padronização, visando mercado internacional.

A agroindústria de exportação tem projetado a carne da Amazônia para grandes redes varejistas e para o mercado internacional. Essas empresas têm chegado à região com objetivo de ter acesso a uma rede de fornecedores de matéria prima (bovinos). A parte 0 crescimento do rebanho e das áreas de pastagens, a pecuária regional vem passando por transformações técnicas que atendem a critérios sanitários e qualitativos que a agroindústria de exportação necessita para atender o consumidor. 0 Brasil tem se especializado nas exportações de cortes in natura de carne bovina, o que implica que o bovino fornecido tem papel determinante em atender à exigência do mercado. Portanto, o pecuarista precisa estar integrado a essas exigências para atender essa demanda específica.

A cadeia produtiva de carne bovina já experimentou mudanças que ocorreram em função das exigências que o mercado internacional impõe como o controle da febre aftosa, programa de rastreabilidade, entre outros que foram institucionalizados. Assim, a agroindústria está submetendo a produção de carne da Amazônia a este mercado, que já se manifesta contrário a aquisição de carne que tem como origem o desmatamento.

\section{REFERÊNCIAS BIBLIOGRÁFICAS}

BECKER, B. Geopolítica da Amazônia. Estudos Avançados. v. 19, n. 53, p. 71-86, 2005.

BRASIL. Ministério da Agricultura, Pecuária e Abastecimento. História do MAPA. 2009a. Disponível em: $<$ http://www.agricultura.gov.br>. Acesso em: 20 nov. 2009.

COSTA, F. de A. Formação Agropecuária da Amazônia: os desafios do desenvolvimento sustentável. Belém: NAEA, 2000.

DINIZ, C. C. Repensando a questão regional brasileira: tendências, desafios e caminhos. In: CASTRO, A. C. (Org.). Desenvolvimento em debate: painéis do desenvolvimento brasileiro II. Rio de Janeiro: BNDES, 2002. v. 3. p. 239-274

FEARNSIDE, P.M. Desmatamento na Amazônia brasileira: história, índices e consequências. MEGADIVERSIDADE. v. 1, n. 1, p. 113-123, jul. 2005.

FÜRSTENAU, V. Pecuária: atraso ou modernização. Indicadores Econômicos FEE, Porto Alegre, FEE, v. 22, n. 4, p. 252-272, 1995.

IANNI, O. Ditadura e Agricultura: o desenvolvimento do capitalismo na Amazônia (1964-1978). 2. ed. Rio de Janeiro: Civilização Brasileira, 1986.

IBGE. Censo Agropecuário 2006. Rio de Janeiro: IBGE, 2009.

Revista de Estudos Sociais - Ano 2013, Nro 29, Vol 15 Pag. 95 
IEL (INSTITUTO EUVALDO LODI). Estudo sobre a eficiência econômica e competitividade da cadeia agroindustrial da pecuária de corte no Brasil. Brasília, 2000.

JANK, M. S. Competitividade do Agribusiness Brasileiro: discussão teórica e evidências no sistema de carnes 1996. 195 f. Tese (Doutorado em Administração) - Universidade de São Paulo, São Paulo, 1996.

MAHAR, D. J. Desenvolvimento Econômico da Amazônia: uma análise das políticas governamentais. Rio de Janeiro: IPEA;INPES, 1978.

MARGULIS, S. Causas do desmatamento da Amazônia brasileira. Brasília, DF: Banco Mundial, 2003.

MAZZALI, L. O processo recente de reorganização agroindustrial: do complexo à organização "em rede". São Paulo: Editora UNESP, 2000

NEVES, M.F. et al. Redes Agroalimentares \& Marketing da Carne Bovina em 2010. In: CONGRESSO BRASILEIRO DAS RAÇAS ZEBUÍNAS, 4., 2000, Uberaba. Anais eletrônicos... Uberaba, 2000. Disponível em: $<w w w$.favaneves.org/arquivos/redecarnes.pdf>. Acesso em: 25 mar. 2010.

PAULA, J. A. de. Amazônia: Fronteira de Acumulação de Capital. In: RIVERO, S.; JAYME JR, F. G. (Org.). As Amazônias do Século XXI. Belém: EDUFPA, 2008. p. 17-39.

PEREZ, R. Uma análise exploratória da competitividade e agregação de valor da cadeia produtiva de carne bovina no Brasil, com ênfase no segmento de abate e processamento. 2003. $336 \mathrm{f}$. Tese (Doutorado em Engenharia de Alimentos) - Universidade Estadual de Campinas, Campinas, 2003.

POSSAS, M. L. Estruturas de Mercado em Oligopólio. 2. ed. São Paulo: HUCITEC, 1990.

SANTOS, M. A. S. dos. et al. Mercado e Dinâmica Local da Cadeia Produtiva da Pecuária de Corte na Região Norte. Belém: BASA, 2007. (Estudos Setoriais, 1).

SERRA, M. A.; FERNÁNDEZ, R. G. Perspectivas de desenvolvimento da Amazônia: motivos para o otimismo e o pessimismo. Economia e Sociedade. v. 13, n. 2 (23), p. 107-131, 2004.

SILVA, J. G. da. A modernização dolorosa: estrutura agrária, fronteira agrícola e trabalhadores rurais no Brasil. Rio de Janeiro: Zahar, 1982

USDA. Statistics of Agriculture. 2009. Disponivel em: <http://www.usda.gov/wps/portal/usdahome>. Acesso em: 20 nov. 2009.

VELHO, O. G. Frentes de expansão e estrutura agrária: Estudo do processo de penetração numa área da Transamazônica. Rio de Janeiro: Zahar Ed., 1972.

WILKINSON, J.; ROCHA, R. Uma análise dos setores de carne bovina, suína e de frango. Roteiro dos estudos econômicos setoriais. Rio de Janeiro: Projeto SENAI;UFRJ, 2005. 